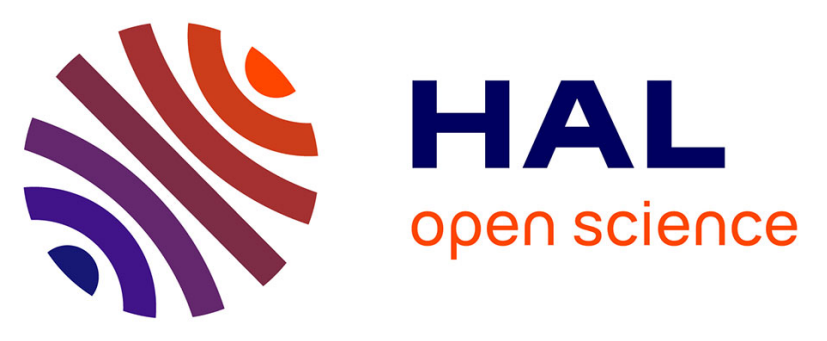

\title{
Investigations on electro-optical and thermal performances degradation of high power density GaAs-based laser diode in vacuum environment
}

J. Michaud, G. Pedroza, L. Béchou, L.S. How, O. Gilard, D. Veyrié, F. Laruelle, S. Grauby

\section{To cite this version:}

J. Michaud, G. Pedroza, L. Béchou, L.S. How, O. Gilard, et al.. Investigations on electro-optical and thermal performances degradation of high power density GaAs-based laser diode in vacuum environment. Microelectronics Reliability, 2015, 55 (9-10), pp.1746-1749. 10.1016/j.microrel.2015.06.068 . hal-01256856

\section{HAL Id: hal-01256856 https://hal.science/hal-01256856}

Submitted on 15 Jan 2016

HAL is a multi-disciplinary open access archive for the deposit and dissemination of scientific research documents, whether they are published or not. The documents may come from teaching and research institutions in France or abroad, or from public or private research centers.
L'archive ouverte pluridisciplinaire HAL, est destinée au dépôt et à la diffusion de documents scientifiques de niveau recherche, publiés ou non, émanant des établissements d'enseignement et de recherche français ou étrangers, des laboratoires publics ou privés.

\section{(1)(1) $\$(0)$}

Distributed under a Creative Commons Attribution - NonCommercial - ShareAlikel 4.0 


\title{
Investigations on electro-optical and thermal performances degradation of high power density GaAs-based laser diode in vacuum environment
}

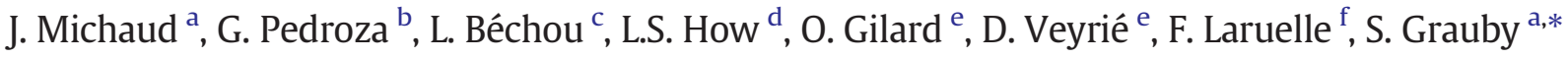 \\ a Université de Bordeaux, LOMA, UMR 5798, 33405 Talence, France \\ b ALPHANOV, Rue François Mitterrand, 33400 Talence, France \\ c Université de Bordeaux, IMS, UMR 5218, 33405 Talence, France \\ d AdvEOTec, 6 Rue de la Closerie, 91090 Lisses, France \\ e CNES, 18, Avenue Belin, 31041 Toulouse Cedex 4, France \\ f 3 S Photonics, Route de Villejust, 91625 Nozay, France
}

Keywords:

Laser diode

Thermal mapping

Thermoreflectance

Electro-optical characterization

Vacuum

\begin{abstract}
A B S T R A C T
Pump laser diodes emitting at $980 \mathrm{~nm}$ are typically used in distribution network transmission systems and are now implemented in space missions for intra satellite communication links and calibration systems. Neverthe less, since the pump source is potentially a critical point for such systems, there is a huge need to assess their re liability in space environment, especially in terms of operation under vacuum conditions. We have then studied the electro optical behavior of several $980 \mathrm{~nm}$ laser diodes and shown that they may degrade more rapidly when submitted to a vacuum environment. Then, spatially resolved temperature variations have been measured by thermoreflectance on the laser diode front facet and have shown a temperature variation increase under vacuum conditions, in particular near the emission region, where a catastrophic optical damage is most likely to occur. This temperature variation increase could then be one of the causes for the more rapid laser diode degradation.
\end{abstract}

\section{Context and motivation}

High power density GaAs based pump laser diodes emitting at $980 \mathrm{~nm}$ are typically used in optical network transmission systems in Erbium Doped Fiber Amplifiers [1] for long distance and large capacity optical telecommunication systems. Such devices are also used in space missions for Fiber Optic Gyroscopes, and intra satellite communication links [2]. However as the pump diode is potentially a critical point for such systems, there is a huge need to assess their reliability in space en vironment, especially in terms of operation under vacuum conditions.

Some published studies $[3,4]$ have already been reported on qualifi cation testing of high power $808 \mathrm{~nm}$ pump laser diodes arrays in vacu um environment. No catastrophic failures were observed and the authors concluded that the laser diodes are robust enough to survive in the harsh space environment. However up to now, long term in vacuum reliability testing of $980 \mathrm{~nm}$ laser diodes was never clearly addressed. Because the chip is embedded into a sealed package, it is not directly exposed to vacuum environment but depending on the package leak rate, the internal pressure may vary from its initial value to the external pressure one.

The study presented here takes part of a full evaluation program managed by the French Space Agency (CNES) with a specific focus on

\footnotetext{
* Corresponding author.

E-mail address: stephane.grauby@u-bordeaux.fr (S. Grauby).
}

long term CW aging of $980 \mathrm{~nm}$ laser modules under vacuum. The chip is a spatially single mode $980 \mathrm{~nm}$ laser diode housed in a hermetically sealed butterfly package with dual lens coupling optics. Eight packaged diodes were studied and among them, four were specifically punctured before the aging test to accelerate the out diffusion of gaseous contents and to simulate the behavior of the laser diode after a long high vacuum exposition at $10^{-7} \mathrm{mbar}$. After the test, the non punctured components are fully operational whereas three out of four modules, of the punc tured group, suddenly failed.

In a previous paper [5], we investigated the main mechanism origi nating from the failure. For that, ToF SIMS measurements revealed no significant evidence of organic contamination in relation with the pack age puncturing. This allows us to discard a Particle Induced Failure (PIF) hypothesis and assume that the vacuum test system or the laser diode package itself is unlikely to be at the origin of the failure. Dark lines were identified inside the bulk using cathodoluminescence $(\mathrm{CL})$ mea surements corresponding to local non radiative recombination centers. Specific FIB prepared samples were analyzed by TEM and revealed a quantum well melting/re solidification. The increase of temperature due to zero convection in vacuum may be the probable root cause of degradation. We must point out that these failures occurred only on punctured devices and were not observed on hermetic devices. With this past study, we concluded that dual lens optical alignment type, as included in such laser modules, featuring a measured leak rate close to $10^{-10} \mathrm{~atm} \cdot \mathrm{cm}^{3} / \mathrm{s}$ are able to withstand reliable operation in high 
vacuum level during at least ten years but the main origin of the failure occurring on punctured modules is still unclear and unsolved.

Suspecting a catastrophic optical damage (COD) due to a laser diode front facet temperature increase, presumably due to the lack of convec tion effect, in this paper, we particularly investigate the thermal behav ior of these devices in air and under vacuum. Temperature variations of unpackaged laser diodes are then estimated on different positions of the front facet using a spatially resolved thermoreflectance technique.

\section{Device technology and electro-optical characterization}

\subsection{Device technology}

The active devices under test consist in single AlGaAs/InGaAs quantum well laser diodes emitting at $980 \mathrm{~nm}$ inside a hermetically sealed butterfly package with dual lens optics. Fig. 1 gives a basic cross section scheme of the device front facet. The $3.9 \mathrm{~mm}$ long ridge structure, covered by a gold layer, allows us to confine the cur rent and the light emission in the quantum well of the active region at the $\mathrm{p} n$ junction, thus reducing the threshold current. Operating under a monomode spectrum, the module includes a wavelength locking process based on a Fiber Bragg Grating inscribed in a Polari zation Maintaining Fiber, providing an excellent stability and very wide dynamic range.

Such modules also contain a back facet photodiode for monitoring purposes and a getter. The reference operating conditions are $40{ }^{\circ} \mathrm{C}$ for a $500 \mathrm{~mA}$ nominal current, leading to a $300 \mathrm{~mW}$ optical power.

\subsection{Electro optical characterization}

The electro optical characterizations were performed on eight mod ules in a vacuum chamber. They consisted in optical power, monitoring photodiode current and voltage versus driving current measurements (L Q V I), spectrum measurements and low level current versus volt age characteristics (I V). Fig. 2 shows typical initial (i.e., before aging) L Q V I characteristics in air and vacuum $\left(10^{-7} \mathrm{mbar}\right)$ of a laser diode at $25{ }^{\circ} \mathrm{C}$. One can notice that these curves are typical for a $980 \mathrm{~nm}$ pump laser diode and no basic kink effect is observable [6,7]. Then, their optical spectrum in air and vacuum at $25^{\circ} \mathrm{C}$ and $500 \mathrm{~mA}$ was mea sured. Both spectra are very similar and the power in band is greater than $99.9 \%$ which suggests that the Bragg grating peak wavelength is correctly locked with the emission spectrum of the laser chip.

The aging tests were performed at $60{ }^{\circ} \mathrm{C}$ and $800 \mathrm{~mA}$ during almost $5000 \mathrm{~h}$ under a $10^{-7}$ mbar pressure. Among the eight modules, LD1 to LD4 were kept sealed and LD5 to LD8 were punctured. The tracking of the optical power variation of the eight laser diodes in vacuum is shown in Fig. 3. Three punctured components (LD5, LD6 and LD7) sud denly failed before the end of the planned aging period. The optical power and photodiode current dramatically dropped whereas the

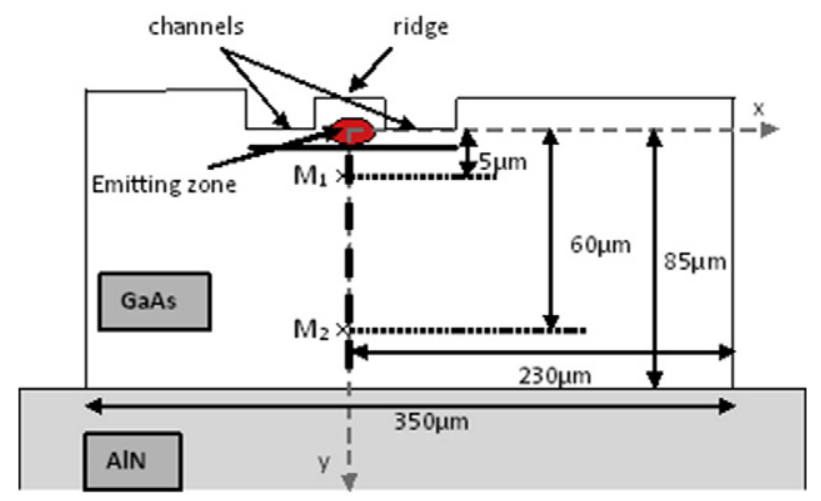

Fig. 1. Generic facet view of the $980 \mathrm{~nm}$ laser diode.

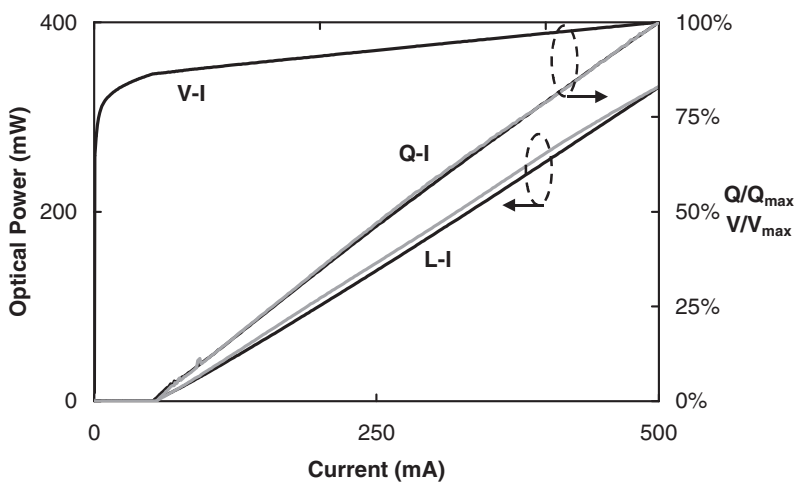

Fig. 2. Typical L-Q-V-I characteristics in air (black) and vacuum (gray) at $25^{\circ} \mathrm{C}$.

laser voltage slightly increased after $1037 \mathrm{~h}$ of operation for LD5, $1934 \mathrm{~h}$ for LD6 and $2227 \mathrm{~h}$ for LD8. The degradation is sudden instead of gradual suggesting a COD phenomenon. No sealed component failed during the aging. It clearly demonstrates the influence of high level vacuum testing and the fastest catastrophic drop of the opti cal power in comparison of aging tests in air using the same conditions ( $\gg 5000 \mathrm{~h}$ ). Since the key parameter leading to a COD may be a front facet temperature increase, a non contact and non invasive technique offering submicrometric spatial resolution capabilities, namely optical thermoreflectance, was applied on unpackaged $980 \mathrm{~nm}$ laser diodes to accurately characterize the thermal behavior on the front facet both in air and in vacuum.

\section{Thermal characterization}

\subsection{Thermoreflectance experimental set up}

To evaluate the temperature variations to which the functioning laser diode is submitted, we use a classical thermoreflectance set up [8]: when the surface of a device or material is submitted to a tempera ture variation $\Delta T$, it induces a relative reflectivity variation $\Delta R / R$ propor tional to $\Delta \mathrm{T}$. Then, probing the surface with a laser beam, the relative intensity variation of the reflected beam can be measured and $\Delta R / R$ is extracted. Among thermal mapping methods, thermoreflectance is an accurate, non contact and non invasive method. Its spatial resolution is limited by diffraction and depends on the probe wavelength and on the optical equipment used. Under visible illumination, it is classically micrometric but can reach a few hundred nanometers with a high nu merical aperture objective. In our case, the diode is biased using a ITC510 current source, allowing to adjust the operating point, connect ed with a 33250 A voltage generator to modulate the driving current

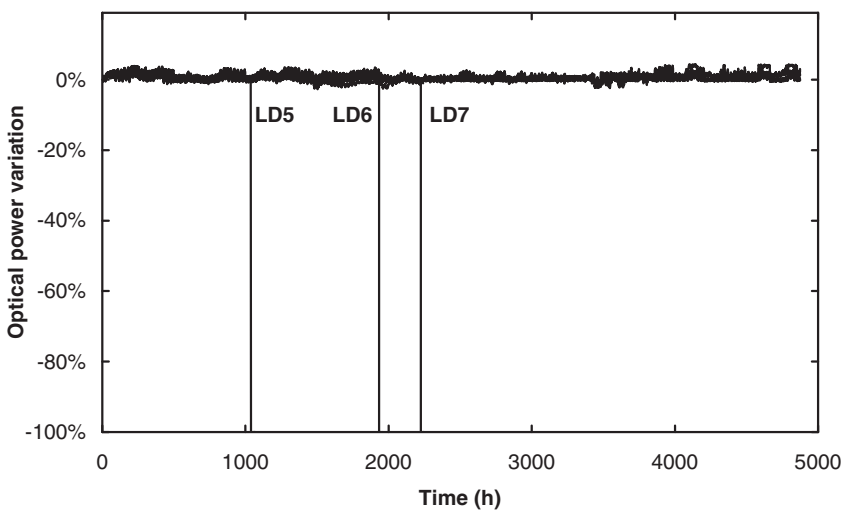

Fig. 3. Monitoring of the optical power variations during vacuum life test $\left(800 \mathrm{~mA}, 60^{\circ} \mathrm{C}\right.$ and $10{ }^{7}$ mbar). 


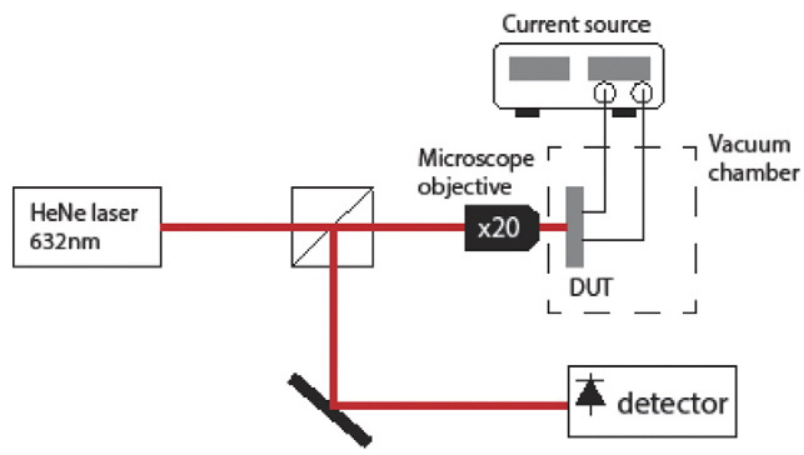

Fig. 4. Schematic of the thermoreflectance set-up.

which is a $50 \%$ duty cycle square current ( $\mathrm{f}=442 \mathrm{~Hz}$ ) varying from $0.1 \mathrm{~mA}$ to $\mathrm{I}_{\max } ; \mathrm{I}_{\max }$ can be adjusted from $6 \mathrm{~mA}$ to $1 \mathrm{~A}$. Then, the electrical power is mainly dissipated at frequency $\mathrm{f}$, which induces a temperature variation at the same frequency $\Delta \mathrm{T}_{\mathrm{f}}$, and consequently a reflectivity var iation $\Delta \mathrm{R}_{\mathrm{f}}$. The relative reflectivity variation is related to $\Delta \mathrm{T}_{\mathrm{f}}$ according to Eq. (1):

$\frac{\Delta \mathrm{R}_{\mathrm{f}}}{\mathrm{R}} \quad \frac{1}{\mathrm{R}} \frac{\partial \mathrm{R}}{\partial \mathrm{T}} \Delta \mathrm{T}_{\mathrm{f}} \quad \kappa \times \Delta \mathrm{T}_{\mathrm{f}}$

where $\mathrm{R}$ is the sample mean reflectivity and $\kappa$ is the thermoreflectance coefficient mainly depending on the nature of the material and on the probe beam wavelength. Subsequently, $\Delta \mathrm{R}_{\mathrm{f}} / \mathrm{R}$ and $\Delta \mathrm{T}_{\mathrm{f}}$ are simply noted $\Delta R / R$ and $\Delta T$, respectively.

A schematic of the thermoreflectance set up is presented in Fig. 4. A probe laser beam ( $\mathrm{He} \mathrm{Ne}$ ) at $\lambda=632 \mathrm{~nm}$, for which the thermoreflectance coefficient $\kappa$ has been measured to be maximum, is focused by a $\times 20$ magnification and 0.3 numerical aperture micro scope objective on the front facet of the unpackaged laser diode and then reflected at its surface. Then, the relative intensity variation $\Delta \mathrm{I} / \mathrm{I}$ of the reflected probe, which directly gives $\Delta R / R$, is measured by a photodiode. The spot diameter, which limits the spatial resolution, was evaluated to $3 \mu \mathrm{m}$ approximately and the $\Delta \mathrm{R} / \mathrm{R}$ set up sensitivity was measured to be as low as $2 \times 10^{-6}$. To operate under vacuum, we added to the detailed set up described in [9] a vacuum chamber where the laser diode under test is positioned. This chamber can work down to $10^{-6}$ mbar. When the device is positioned in the chamber, its pressure is stabilized around $3 \times 10^{-5} \mathrm{mbar}$, and the measurements under vacuum presented subsequently are per formed at this pressure value. In addition, the vacuum chamber is equipped with a micrometric translation stage to displace the laser diode under test.

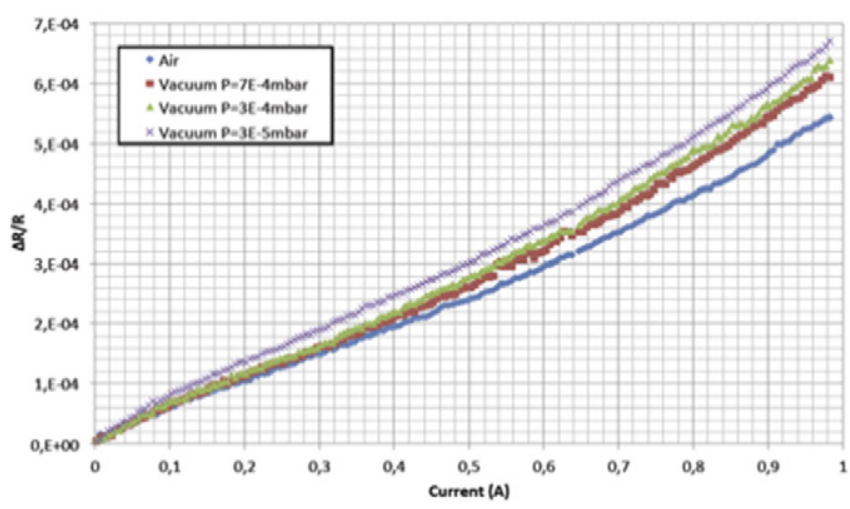

Fig. 5. Thermoreflectance signal versus bias current for different vacuum levels.

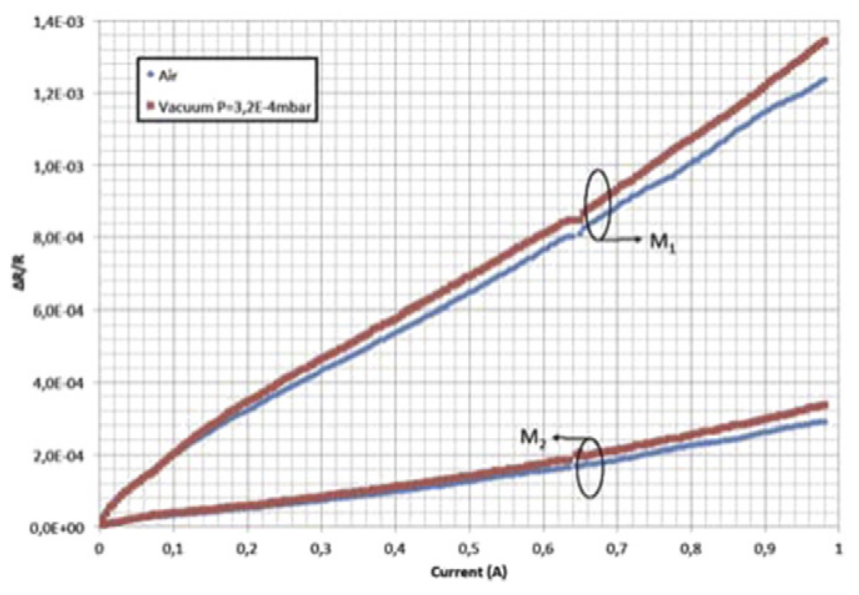

Fig. 6. Thermoreflectance signal versus bias current in air and vacuum for two different locations in the laser diode front facet.

\subsection{Vacuum influence on the thermoreflectance signal}

First, the thermoreflectance signal is measured as a function of the bias current, $I_{\max }$ varying from $6 \mathrm{~mA}$ to 1 A with a $3 \mathrm{~mA}$ step when the probe beam is focused at $\mathrm{y}=10 \mu \mathrm{m}$ on the $\mathrm{y}$ axis. This measurement was done for 4 different pressure levels: atmospheric pressure, $7 \times 10^{-4}$ mbar, $3 \times 10^{-4}$ mbar and $3 \times 10^{-5}$ mbar as plotted in Fig. 5 .

When the pressure level decreases, we clearly note an increase of the thermoreflectance signal, thus of the temperature variation, up to $20 \%$. A pressure influence is then obvious. Subsequently, all the "vacuum" measurements are done under a $3.2 \times 10^{-5}$ mbar pressure.

\subsection{Temperature variation measurements}

All the measurements presented below are done on 3 laser diodes and repeated three times. The curves correspond to the calculated mean values.

\subsubsection{Influence of the bias current on the thermoreflectance signal}

We first focused on two positions $\mathrm{M}_{1}$ and $\mathrm{M}_{2}$, respectively about $5 \mu \mathrm{m}$ and $60 \mu \mathrm{m}$ away from the emitting source on the y axis (see Fig. 1). Then the thermoreflectance signal is monitored as a function of the bias current $\mathrm{I}_{\max }$ varying from $6 \mathrm{~mA}$ to $1 \mathrm{~A}$ with a $3 \mathrm{~mA}$ step (see Fig. 6). Table 1 summarizes the main results obtained under at mospheric conditions and under vacuum. We note that the mean thermoreflectance signal between the threshold current and I = $1 \mathrm{~A}$ increases under vacuum by $6.7 \%$ and $13.8 \%$ at positions $\mathrm{M}_{1}$ and $\mathrm{M}_{2}$, respectively, but the increase can, respectively, reach $8.9 \%$ and $15.6 \%$ at maximum current $\mathrm{I}=1 \mathrm{~A}$.

Even if the increase is higher at position $\mathrm{M}_{2}$, it is less critical than for position $\mathrm{M}_{1}$, for which the absolute thermoreflectance signal, therefore the absolute temperature variation, is higher.

Table 1

Thermoreflectance measurements in air and under vacuum.

\begin{tabular}{llcll}
\hline & $\begin{array}{l}\Delta \mathrm{R} / \mathrm{R}(\mathrm{I}=0.3 \mathrm{~A}) \\
\left(\times 10^{4}\right)\end{array}$ & $\begin{array}{l}\Delta \mathrm{R} / \mathrm{R}(\mathrm{I}=1 \mathrm{~A}) \\
\left(\times 10^{4}\right)\end{array}$ & $\begin{array}{l}\Delta \mathrm{R} / \mathrm{R} \text { increase } \\
\text { ratio }(\mathrm{I}=1 \mathrm{~A}) \\
(\%)\end{array}$ & $\begin{array}{l}\text { Mean } \Delta \mathrm{R} / \mathrm{R} \\
\text { increase ratio } \\
(\%)\end{array}$ \\
\hline $\mathrm{M}_{1}$ (air) & 4.3 & 12.3 & & \\
$\mathrm{M}_{2}$ (air) & 0.73 & 2.90 & & 6.7 \\
$\mathrm{M}_{1}$ (vac) & 4.63 & 13.4 & 8.9 & 13.8 \\
$\mathrm{M}_{2}$ (vac) & 0.82 & 3.35 & 15.6 & \\
\hline
\end{tabular}




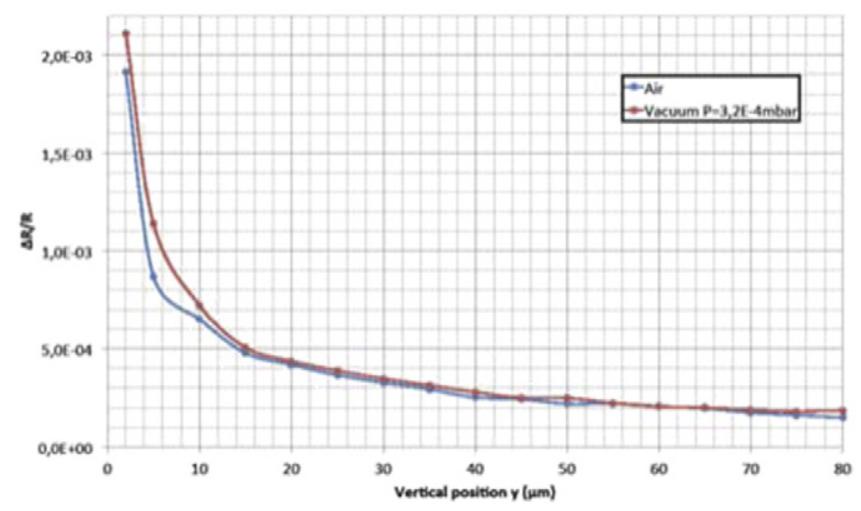

Fig. 7. Thermoreflectance signal along the $y$ axis at $\mathrm{I}=800 \mathrm{~mA}$.

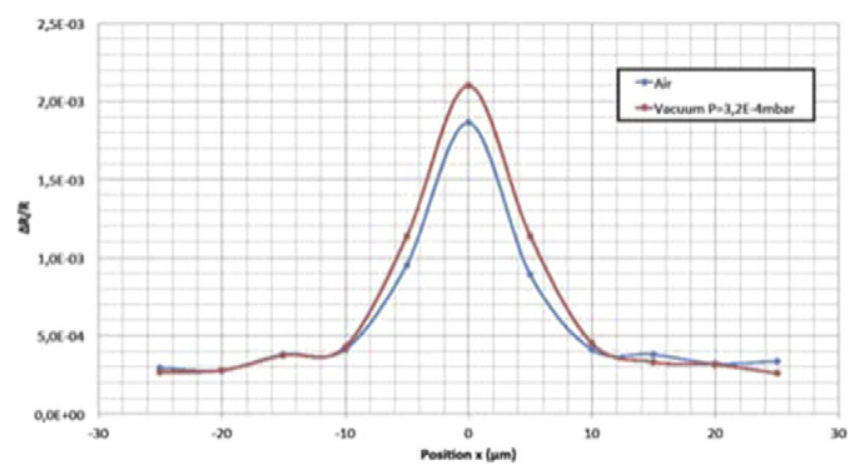

Fig. 8. Thermoreflectance signal scan $(\mathrm{y}=2 \mu \mathrm{m}, \quad 25 \mu \mathrm{m}<\mathrm{x}<25 \mu \mathrm{m})$ at $\mathrm{I}=800 \mathrm{~mA}$.

\subsubsection{Thermoreflectance signal scans}

The objective of this work is also to assess, as accurately as possible, the temperature distribution at the output facet.

For that, the relative reflectivity variation is measured along the ver tical axis y when $\mathrm{I}_{\max }=800 \mathrm{~mA}$ (see Fig. 7). The first point $(\mathrm{y}=2 \mu \mathrm{m})$ corresponds to the bottom of the emitting source towards the AlN heat sink. The displacement step is $3 \mu \mathrm{m}$ for the first step and then $5 \mu \mathrm{m}$ be tween $\mathrm{y}=5$ and $80 \mu \mathrm{m}$. We clearly see that the thermoreflectance sig nal, hence the temperature variation, is higher under vacuum than in air. The signal increase reaches a mean value of almost $10 \%$ along the whole scan and reaches $31 \%$ in the close vicinity of the emitting source between $\mathrm{y}=2 \mu \mathrm{m}$ and $\mathrm{y}=10 \mu \mathrm{m}$. We also measured (see Fig. 8) the thermoreflectance signal on a horizontal scan, along the black horizon tal full line (see Fig. 1), for $\mathrm{y}=2 \mu \mathrm{m}$ and between $\mathrm{x}=-25 \mu \mathrm{m}$ and $\mathrm{x}=$ $25 \mu \mathrm{m}$ with a $5 \mu \mathrm{m}$ step. Here again, we noted a thermoreflectance signal increase, when measuring under vacuum, reaching $27 \%$ near the emit ting zone (around $\mathrm{x}=0$ ) and a mean value of $14 \%$ between $\mathrm{x}=-10 \mu \mathrm{m}$ and $\mathrm{x}=10 \mu \mathrm{m}$.

\section{Conclusion}

Electro optical measurements have shown that laser diode modules submitted to vacuum conditions seemed to undergo a COD more rapid ly than in air. Thermoreflectance measurements have confirmed that the temperature variations of the front facet are higher under vacuum, with an increase reaching around $30 \%$ close to the active region, which could constitute one of the possible causes for an early degrada tion of the laser diodes. Further investigations must be conducted to study other possible causes of failure.

\section{Acknowledgments}

The authors would like to warmly thank Dr J.L. Gauffier and S. Reyjal from the Department of Physics Engineering at INSA Toulouse, for the design of the dedicated vacuum chamber used in this study.

\section{References}

[1] E. Desurvire, J.R. Simpson, P.C. Becker, High-gain erbium-doped traveling-wave fiber amplifier, Opt. Lett. 12 (1987) 888-890.

[2] S. Rougelot, S. Mariojouls, T. Buret, D. Ramecourt, X. Calmet, Procurement and qualification of optical components for space fibre optic gyroscope application, Proc. 1st Int. Symp. On Reliab. Of Optoelectronics for Space ISROS 09. Cagliari 2009, pp. 231-236.

[3] E. Troupaki, A. Vasilyev, N.B. Kashem, G.R. Allan, M.A. Stephen, Space qualification and environmental testing of quasicontinuous wave laser diode arrays, J. Appl. Phys. 100 (2006) 063109-5.

[4] Y. Durand, A. Culoma, R. Meynart, J.L. Pinsard, G. Volluet, Performance of high-power laser diode arrays for spaceborne lasers, Appl. Opt. 45 (2006) 5752-5757.

[5] G. Pedroza, L. Bechou, Y. Ousten, L.S. How, O. Gilard, J.L. Goudard, F. Laruelle, Long term in-vacuum reliability testing of $980 \mathrm{~nm}$ laser diode pump modules for space applications, 35th IEEE Aerospace Conference, march 2014, Big Sky, MT, USA, 2014.

[6] M.A. Bettiati, C. Starck, F. Laruelle, V. Cargemel, P. Pagnod, P. Garabedian, D. Keller, G. Ughetto, J.C. Bertreux, L. Raymond, G. Gelly, R.M. Capella, Very high power operation of $980 \mathrm{~nm}$ single-mode InGaAs/AlGaAs pump lasers, Proc. SPIE 2006, p. 6104.

[7] G. Yang, V. Wong, V. Rossin, L. Xu, M. Everett, J. Hser, D. Zou, J. Skidmore, E. Sucker, Grating stabilized high power $980 \mathrm{~nm}$ pump modules, Conf. Rec. Opt. Fiber Communication and the National Fiber Optic Engineers Conf., Mar 2007, pp. 1-3.

[8] S. Dilhaire, S. Grauby, W. Claeys, Thermoreflectance calibration procedure on a laser diode: application to catastrophic optical facet damage analysis, IEEE Electron Device Lett. 26 (2005) 461-463.

[9] J. Michaud, P. Del Vecchio, L. Bechou, D. Veyrie, M.A. Bettiati, F. Laruelle, S. Grauby, Precise facet distribution of high power laser diodes: unpumped window effect, IEEE Photon. Technol. Lett. (2015)http://dx.doi.org/10.1109/LPT.2015.2405090. 